\title{
DAS NOVAS TEXTUALIDADES ÀS NOVAS PRÁTICAS DE LEITURA: comunicação, tecnologia e semiótica
}

\author{
From new textualities to new readings practices: \\ communication, technology and semiotic
}

\section{Edson Fernando Dalmonte}

Doutor em comunicação e cultura contemporâneas, Universidade Federal da Bahia (Facom/UFBA), Coordenador do curso de Jornalismo da Faculdade Social, professor de Teorias da Comunicação. Pesquisador do Cepad - Centro de Estudos e Pesquisa em Análise do Discurso, Universidade Federal da Bahia (Facom/UFBA), Salvador, BA - Brasil, e-mail: edsondalmonte@uol.com.br

\begin{abstract}
Resumo
No contexto atual da comunicação de massa, caracterizado pela convergência tecnológica, o presente artigo tem por objetivo discutir o conceito de texto sob duas perspectivas: 1) o texto semiótico, como resultado da articulação de intencionalidades e propostas de itinerários de leitura. Para que se possa construir a chamada função sígnica, responsável por marcar a correlação entre a forma de conteúdo e a forma da expressão, e por consequência chegar à noção de texto, é preciso tomar uma decisão, ou seja, estabelecer a distinção entre sistema de significação e processo de comunicação; 2) o texto sob o ponto de vista da pragmática tecnológica que propicia a fusão de modalidades textuais distintas, que passam a compor blocos fluidos de texto. Logo, aborda-se o texto não como elemento que se abre a múltiplas interpretações, mas como elemento capaz de suscitar uma mobilização de quem o lê, ou seja, uma performance prevista. A partir dos questionamentos advindos do encontro do leitor com o texto em novas plataformas, indaga sobre os novos regimes de significação.
\end{abstract}

Palavras-chave: Jornalismo. Tecnologia. Semiótica textual.

\begin{abstract}
In the current context of mass media, characterized by technological convergence, this paper aims to discuss the concept of text from two perspectives: 1) the semiotic text, as a result of joint intentions and proposed routes of reading. To be able to build the call sign function, responsible for checking the correlation between the form of content and form of expression, and consequently arrive at the notion of text, you need to make a decision, ie the distinction between signifying system and communication process, 2) the text as saw by the technologic pragmatics that permits
\end{abstract}


the fusion of different kinds of textual modalities composing fluid blocks of text. Therefore, it approaches the text as an element that is open to multiple interpretations, but as an opportunity to raise a mobilization of its reader, or a performance planned. After questions from the reader's encounter with the text on new platforms, it inquires about the new systems of meaning.

Keywords: Journalism. Technology. Textual semiotic.

Ao tomarmos por parâmetro a relação do público leitor com os produtos da indústria literária, pode-se perceber que há uma preocupação constante dessa indústria em relação a seu público. Nessa mesma linha, surgem outras questões, como as que são propostas por uma nova forma de consumir o texto, mais precisamente, novas modalidades de apropriação e leitura. Com a perspectiva digital, descortina-se toda uma gama de possibilidades quanto à mediação entre texto e leitor. Dessa constatação surgem duas questões fundamentais: os desdobramentos da noção de texto e as novas modalidades de acesso às formas textuais.

Ao falar da questão da textualidade, Umberto Eco (1984, p. 4) apresenta a vinculação entre signo e texto. "Em um sistema semiótico bem organizado um signo já é um texto virtual, e num processo de comunicação um texto nada mais é que a expansão da virtualidade de um sistema de signos."

Já está situada aí a definição de texto, que será trabalhada por Eco, servindo de base para nossos questionamentos quanto às novas modalidades textuais. Então, para que serve um texto? Um texto encontra sua validade na capacidade de registro que estabelece. Por meio do texto, não obstante a variação de seu formato, é possível prolongar o perene, o vivido e facilmente corruptível. Mas, para que essa ruptura com o instantâneo e fugidio se opere, é preciso estabelecer um sistema de significação compatível com o fato, ou coisa retratada, permitindo um contato com o destinatário. Sobre essa relação, diz Eco (1984, p. 6),

Somos animais tais que nunca temos o inteiro universo à nossa disposição. E, portanto, para que possamos nos mover no universo, e falar dele aos outros, somos obrigados a usar entidades materiais presentes (entidades materiais são os sons que emito, são os sinais que deixo na pedra com o giz) para indicar alguma coisa $[. .$.$] que não existe.$
É essa noção de signo, segundo Peirce, como ressalta Santaella (2000), a essência de toda textualidade. Há uma ausência que se presentifica, com base num elemento capaz não de substituir, mas de ao mesmo tempo marcar a falta e estabelecer o lugar daquilo que falta, sem, contudo, ficar no vazio. A questão fundamental aí é o binômio presença/ausência a partir daquilo que falta e é oferecido. É uma carência que é suprida.

Quero pôr as mãos nesse objeto que não existe e que é inapreensível [...] Poderíamos chamar esse objeto inapreensível de sentido ou significado ou, melhor ainda, de conteúdo. Estamos condenados a manipular caixas vazias e, todavia, devemos falar daquele nada que elas contêm, porque aquele nada que está dentro delas é aquele tudo que nos permite viver em sociedade (SANTAELLA, 2000, p. 7).

A questão agora é questionar a forma de suprir a tal carência. Aos olhos de quem o objeto faltoso irá ser substituído? Ora, quem define essa ligação entre a coisa que falta e sua representação é o enunciador. Logo, toda a comunicação humana tem por princípio balizador a construção textual, capaz de representar algo, e assim transportar essa 'coisa' para outras distâncias, de tempo e espaço.

Contudo, a comunicação não é assegurada por uma mera proposta de significação, com base num signo. Para tanto, Eco recorre a Saussure (2006), com base na relação entre significante e significado. Segundo Eco (1984, p. 11), para que se possa construir a chamada função sígnica, que marca a correlação entre a forma de conteúdo e a forma da expressão, e por consequência chegar à noção de texto, é preciso tomar uma decisão, ou seja, estabelecer a distinção entre sistema de significação e processo de comunicação.

Ao sistema de significação equivale o código, que é o elemento comum entre este e o 
processo de comunicação, e que estabelece a ligação entre o enunciador e o destinatário, tendo por referência o código, que é a base da mensagem. O binômio ausência/presença vai ser caracterizado pelo plano do conteúdo, com base nas entidades ausentes; e pelo plano de uma expressão, que tem por parâmetro as entidades presentes (ECO, 1984, p. 12).

A construção de um sistema de significação passa então a ser dependente da organização de planos de expressão e conteúdo. Sendo assim, um elemento presente e às vezes totalmente dissociado daquilo que irá representar, como um dedo da mão, passa arbitrariamente a nomear um elemento ausente. Tem-se aí um sistema de significação que não necessariamente irá passar à categoria de processo de comunicação, estando, contudo, habilitado para tanto.

É interessante notar que para o autor (ECO, 1984, p. 15), “o conceito de texto já é um conceito misto, porque um texto não é um sistema de significação, é uma realização comunicativa. Não se pode, creio, falar de texto em puros termos de sistema de significação.” Essa questão está assentada numa crítica à busca de regras para que se possa gerar um texto, como a 'gramática gerativa', proposta por N. Chomsky (1969). Essa é uma perspectiva que intenta dar conta da criatividade do falante e de sua capacidade de emissão e compreensão de frases inéditas. A linguagem, para Chomsky, tem por referência estruturas universais inerentes ao homem. ${ }^{1}$

Sobre essa relação proposta por Chomsky apud Eco (1984, p. 15), o autor diz que é preciso ir além, ou seja, para 'enfrentar' um texto é preciso que se considere ainda o elemento pragmático, decorrente das circunstâncias a partir das quais o texto foi emitido, bem como a posição de seu enunciador. "O conceito de texto não pode, portanto, ser reservado apenas a uma análise em termos de sistema de significação, pois se trata já de um problema de comunicação."

A busca de compreensão do texto a partir dos 'locais' de sua produção e circulação, fala na verdade da proposta semiótica, que se divide em sintaxe, semântica e pragmática, como proposto por Morris (apud ECO, 1984, p. 15-16). À sintaxe equivalem as regras para a composição das expressões, sem necessariamente depender de seu significado. Ao nível semântico equivale o significado de uma expressão. Já a pragmática trata do possível efeito que determinada expressão pode exercer sobre seu destinatário. "A pragmática, portanto, seria o estudo de como uma expressão, seja ela qual for, depende da natureza do emissor, da natureza do destinatário, do contexto da mensagem e da natureza das circunstâncias externas em que a mensagem é comunicada".

Ainda na ideia da formação de uma textualidade, tendo por base a proposta de um plano de significações, segundo Eco (1984, p. 32), cabe ao signo fazer a mediação entre o objeto imediato e o objeto representado por esse signo - representamen. Essa relação, contudo, marca um empobrecimento em relação ao objeto dinâmico, pois esta é apenas uma representação, que se distancia do real.

Com isso, o signo passa não apenas a representar, mas, sobretudo, a interpretar uma coisa ou situação. Surge assim a função sígnica interpretante.

Peirce introduz uma nova categoria, o Interpretante (Interpretant), que, fique bem claro, não é o intérprete, não é o ser humano que recebe o signo [...] Na sua definição mais simples 'é um signo que substitui outro signo', ou seja, em nossos termos 'é uma expressão que substitui outra expressão’ (ECO, 1984, p. 33).

Sendo assim, o signo, na condição de interpretante, passa a ser o substrato desde o qual todo texto se constitui. E de signo a signo, por aproximação em relação ao que se quer representar, há um enriquecimento, ou aprimoramento desse signo, bem como do representado. "Estabelece-se nesse ponto um processo de semiose ilimitada, pela qual de interpretante a interpretante, através de uma espiral que gradativamente se afunila, enriquecemos cada vez mais de propriedades nosso objeto imediato" (ECO, 1984, p. 34).

\footnotetext{
1 "Nessa perspectiva, a gramática é um mecanismo finito que permite gerar (engendrar) o conjunto infinito das frases gramaticais (bem formadas, corretas) de uma língua, e somente elas. Formada de regras que definem as seqüências de palavras ou de sons permitidos, essa gramática constitui o saber lingüístico dos indivíduos que falam uma língua, isto é, a sua competência lingüística; a utilização particular que cada locutor faz da língua em uma situação particular de comunicação depende da performance "(DUBOIS, 1997, p. 314).
} 
Em linhas gerais, na proposta de Eco, esses são os pressupostos a partir dos quais se constitui a noção de texto, na condição de um plano para a construção de um roteiro de proposta de significações. Mas aqui, antes de nos determos com o processo de captação dessas significações, preocupamo-nos com as modalidades de receber essas textualidades, ou seja, a configuração material do texto, ou seu suporte.

\section{Dos desdobramentos da noção de texto às novas modalidades de acesso às formas textuais}

Para Eco (1984, p. 97), o texto é uma máquina preguiçosa, que não opera sozinha, pois conta com a participação do leitor para preencher os buracos desse tecido que é o texto. A colaboração do leitor possibilita suprimir os não-ditos e assim, completar o texto. Com isso, todo texto prevê seu leitor modelo, com base nos indicativos que são fornecidos.

O leitor-modelo é de certa forma um "tipo ideal que o texto não só prevê como colaborador, mas ainda procura criar. Um texto que começa com 'Era uma vez' envia um sinal que lhe permite de imediato selecionar seu próprio leitor-modelo" (ECO, 1994, p. 15). O leitor em questão pode ser tanto uma criança quanto um adulto que se deixe conduzir por uma história certamente fantasiosa.

Mas para a presente proposta, a noção de leitor modelo bem como de um endereçamento de produtos com base nessa ideia de leitor é secundária, visto que há uma preocupação com o papel de leitor-empírico. Esse papel é exercido por todos os leitores, nas ações cotidianas.

Ao pontuar que para as indagações desse artigo as questões acerca do leitor modelo bem como das interpretações não são o foco principal, o que na verdade se propõe é uma reflexão sobre as novas modalidades de ler, com base nas novas propostas textuais, como no caso da Internet. Logo, a presente empreitada diz respeito ao texto não como elemento que se abre a múltiplas interpretações, mas como elemento capaz de suscitar uma mobilização de quem o lê. Essa mobilização aqui é tratada como performance, como aquela prevista para o momento da recepção, na condição de percepção sensorial, compreendendo o engajamento do corpo nesse processo (ZUMTHOR, 2000, p. 22).

Ao tratar da recepção como condicionante de uma performance, passa-se do texto como proposta de significação, para o texto como elemento histórico, dependente em larga medida da evolução e transmutação de seu suporte, com base nos aportes conceituais oferecidos por Chartier, em especial por suas reflexões sobre o livro e a leitura. A relação de uma performance associada ao ato de leitura marca a afinidade entre os questionamentos de Zumthor e Chartier.

Ao privilegiar os modos de ler e não a leitura como resultado de uma interpretação, buscase localizar ainda assim um ponto comum entre essas modalidades, visto que a interpretação, enquanto processo subjetivo, depende das modalidades da leitura. Cumpre ressaltar que ao tratar das modalidades da leitura, fala-se na verdade do empenho que o indivíduo realiza para 'lidar' com o suporte por meio do qual ele tem acesso ao texto.

Com isso, fala-se do texto como realidade dependente de seu suporte, e que ao longo do tempo a evolução de um marca a evolução do outro. Aí está inserida uma noção de performance associada ao ato de leitura. $\mathrm{O}$ ato de ler deixa de ser visto como apenas a base para uma interpretação, visto que depende também das modalidades de acesso a esse suporte, seja como rolo, livro ou na tela de um computador.

Segundo Zumthor (2000, p. 35),

As regras da performance - com efeito, regendo simultaneamente o tempo, o lugar, a finalidade da transmissão, a ação do locutor e, em ampla medida, a resposta do público importam para comunicação tanto ou ainda mais do que as regras textuais postas na seqüência das frases.

Mas, afinal, de que tipo de performance estamos falando? Zumthor (2000, p. 35) sugere ainda que "performance implica competência". Então, não basta apenas definir performance, há que se buscar ainda o significado de competência. Ao tratar da competência, o autor fala do conjunto de disposições, como psíquicas e de ambiente, que impulsionam não "um 'ler' geral e abstrato mas à leitura do jornal, de um romance ou de um poema" (ZUMTHOR, 2000, p. 38).

Encontra-se aí a definição de uma competência, que se pressupõe fazer parte do leitor. Toda leitura é dependente de um produto, como o jornal ou o romance, que suscitam uma forma distinta de ler. É essa competência do leitor a propulsão para a realização performática da leitura. 
A posição de seu corpo no ato da leitura é determinada, em grande medida, pela pesquisa de uma capacidade máxima de percepção. Você pode ler não importa o que, em que posição, e os ritmos sangüíneos são afetados. É verdade que mal conceberíamos que, lendo em seu quarto, você se ponha a dançar e, no entanto, a dança é o resultado normal da audição poética! (ZUMTHOR, 2000, p. 38).

Com isso, performance pode ser definida como a realização do corpo que capta e vibra com a obra. Mas esse ato dependente da recepção é, por assim se dizer, a conclusão de um processo. Interessa aqui, falar da performance prevista pela obra e inscrita nela. A obra, de acordo com seu gênero, pode suscitar uma reação distinta e essa é a noção de performance que não apenas depende da obra, mas que já vem registrada nela. "Tal é, sem dúvida, a razão pela qual os editores literários tomam geralmente a precaução de imprimir na capa de seus produtos o gênero ao qual eles pertencem: de modo a permitir ao cliente preparar-se para o modo particular de leitura que ele requer!" (ZUMTHOR, 2000, p. 38).

Falar da leitura hoje é falar do fácil manuseio de suportes como o livro ou o jornal. Mas essa forma de acesso aos textos nem sempre foi tão simples, e de acordo com a forma de acesso, tem-se uma forma de leitura, das formas públicas às privadas, e dos formatos que necessitam de uma maior ou menor investida no manuseio desse suporte. Ao tratar do frenesi acerca da revolução proposta pelo texto eletrônico, Chartier (1999a) diz que até meados de 1450 , com a revolução de Gutenberg, um texto só era reproduzido à mão, individualmente. O que tem-se agora é sobretudo a possibilidade de uma maior circulação.

Mas, o livro pós Gutenberg não representa uma revolução com plenas rupturas, em relação aos manuscritos, visto que a mbos baseiam-se numa mesma estrutura fundamental, a do códex.

Tanto um como outro são objetos compostos de folhas dobradas um certo número de vezes, o que determina o formato do livro e a sucessão dos cadernos. Estes cadernos são montados, costurados uns aos outros e protegidos por uma encadernação. A distribuição do texto na superfície da página, os instrumentos que lhe permitem as identificações (paginação, numerações), os índices e os sumários: tudo isto existe desde a época do manuscrito (CHARTIER, 1999a, p. 7-8).
Então, traçar uma historiografia do livro é também tratar das formas de acesso ao suporte material. O texto escrito, em suas origens, que eram dispostos no formato de rolos, pressupunham um maior empenho do leitor, visto que deveria proceder quase que simultaneamente os atos de desenrolar e enrolar o texto. A leitura antiga é radicalmente diferente do que conhecemos e mesmo diferente daquilo que Gutenberg conhecia.

Este livro é um rolo, uma longa faixa de papiro ou de pergaminho que o leitor deve segurar com as duas mãos para poder desenrolá-la. Ele faz aparecer trechos distribuídos em colunas. Assim, um autor não pode escrever ao mesmo tempo que lê. Ou bem ele lê, e suas duas mãos são mobilizadas para segurar o rolo, e nesse caso, ele só pode ditar a um escriba suas reflexões, notas, ou aquilo que the inspira (CHARTIER, 1999a, p. 24).

Tem-se, daí, uma noção de performance inscrita numa obra. $\mathrm{O}$ ato de ler, como resultado de uma apropriação, encontra-se diretamente dependente dessa forma de apropriação. Se o texto, na concepção de Eco (1984, 1994), pressupõe um leitor modelo, numa concepção histórica, da mesma forma o texto prevê um leitor, com base nas possibilidades e limitações inseridas não apenas na obra, enquanto narrativa textual, mas sobretudo tendo-se por referência a condição de acesso ao tipo de suporte.

$\mathrm{O}$ ato de desenrolar um texto ou folhear um livro ou jornal pode caracterizar um tipo de performance, ou seja, um engajamento do corpo no processo. Para aclarar esse ponto, Zumthor (2000, p. 58-59) distingue recepção de performance. Par o autor, "recepção é um termo de compreensão histórica, que designa um processo, implicando pois a consideração de uma duração [...] ela se identifica com a existência real de um texto no seio da comunidade de leitores."

Por outro lado, a performance é diferente, "termo antropológico e não histórico - designa um ato de comunicação como tal; refere-se a um momento tomado como presente" (ZUMTHOR, 2000 , p. 59). Com isso, a performance passa a ser um momento da recepção; momento mesmo no qual um enunciado é recebido.

A recepção aliada à noção de performance marca um momento específico do ato da apreensão de um texto. Todo discurso, segundo Zumthor 
(2000, p. 89), constitui-se num corpo-a-corpo com o mundo. "O mundo me toca, eu sou tocado por ele; ação dupla, reversível, igualmente válida nos dois sentidos".

Aí está a ideia de uma expectativa de performance inscrita no texto, uma vez que o texto desperta no indivíduo a consciência de estar no mundo (ZUMTHOR, 2000, p. 90-91). Então, esse estar no mundo na verdade suscita um sentimento de pertencimento a um quadrante específico. O consumo de todo texto resulta assim das possibilidades de interação com a materialidade da obra.

\section{Do leitor estático ao navegante}

Uma das rupturas apresentada pela inscrição eletrônica diz respeito ao manuseio, que antes era direto. $\mathrm{O}$ texto era desenrolado; a leitura pressupunha um fluxo contínuo; havia fronteiras visíveis, com cadernos, seções, encerrado em capas. Agora, o texto eletrônico abre a possibilidade de embaralhar, entrecruzar e reunir textos. "Todos esses traços indicam que a revolução do livro eletrônico é uma revolução nas estruturas do suporte material do escrito como nas maneiras de ler" (CHARTIER, 1999a, p. 13).

Nessa perspectiva, como é caracterizado então o ato de ler, mediante as novas formas de apresentação e distribuição textual, a partir das possibilidades de registros digitais? "O texto eletrônico reintroduz na escrita alguma coisa das línguas formais que buscavam uma linguagem simbólica capaz de representar adequadamente os procedimentos do pensamento" (CHARTIER, 2002, p. 16).

Sendo assim, a revolução não está apenas na forma de inscrever e disponibilizar o texto; ela pressupõe, sobretudo, uma outra forma de apropriação e leitura desse material. Se acreditamos que a organização do texto, dependente de sua disponibilização num formato, suscita uma forma de ler, como no caso dos rolos ou das edições no formato de códex, como fica essa situação agora, uma vez que os textos passam a estar dispersos, e organizados de forma não-linear, e dispostos em distintos níveis, de acordo com a disponibilidade de bancos de dados?
Essa outra organização textual ao pressupor uma outra forma de acesso, viabiliza outras formas de leitura, o que por sua vez resulta numa nova performance de leitura. Esse novo momento performático pode ser ilustrado pelas possibilidades que são abertas ao leitor-navegador, em especial o público jovem, que ora protagoniza essa inovação. Por exemplo, a nova organização textual eletrônica esboça um novo idioma que é imediatamente reconhecível por todos.

É o caso da invenção dos símbolos, os emoticons, como se diz em inglês, que utilizam de maneira pictográfica alguns caracteres do teclado (parênteses, vírgula, ponto e vírgula, dois pontos) paraindicar o registro de significado das palavras: alegria $^{2}$ :-) tristeza :-(ironia ;-) ira :-@ ... ilustram a procura de uma linguagem não-verbal e que, por essa mesma razão, possa permitir a comunicação universal das emoções e o sentido do discurso (CHARTIER, 2002, p. 17).

Mediante isso, passa-se à constatação de que há de fato uma modificação nas formas de leitura, o que não quer dizer exatamente uma diminuição dessa prática. Há sim, novas modalidades de leitura, por vezes operando a partir de elementos mais fragmentados. Quando se fala da redução do índice de leitura, na verdade não se atenta para as modalidades que divergem das tradicionais formas de leitura. "É preciso utilizar aquilo que a norma escolar rejeita como um suporte para dar acesso à leitura na sua plenitude, isto é, ao encontro de textos densos e mais capazes de transformar a visão do mundo, as maneiras de sentir e de pensar" (CHARTIER, 1999a, p. 104).

Tratar das identidades de cada suporte é discutir, fundamentalmente, essa noção de evolução de um meio, em especial quanto a sua identidade a partir de sua materialidade. Nesse mesmo sentido, a evolução do jornal é também marcada pelas modificações inerentes às definições de seu suporte. Segundo Chartier (1999a, p. 82), nos séculos XVII e XVIII, o jornal e o livro mantinham uma mesma estrutura. É só quando o jornal adquire um formato maior e uma ampla circulação que o seu suporte material terá um tratamento mais livre, passando a ser carregado, dobrado, consumido por muitos e até mesmo rasgado.

\footnotetext{
2 O Windows já está habilitado para substituir os sinais de pontuação por desenhos, como alegria :-) - (;) e tristeza :-( -
} 
Estamos diante de um outro tipo de suporte, o jornal diário, que apresenta um texto mais efêmero, que pode ser dobrado, riscado ou descartado. Esse suporte pode ser manipulado de forma distinta. E quanto às novas possibilidades eletrônicas, o que elas sugerem? O jornal impresso, tal qual o conhecemos há tempos, hoje é totalmente produzido por meio eletrônicos, estando aí armazenado até sua confecção final. Estamos, com isso, no limiar de mudanças quanto à finalização e distribuição desse material.

Se antes o jornal podia ser recortado e jogado fora, da mesma forma, de acordo com os recursos digitais, um material pode ser selecionado, recortado, copiado, e pode ser arquivado, e o restante pode ser apagado. Da mesma forma, uma vez que já dispomos das possibilidades de produção e de canais para a distribuição desse material digital, "por que não pensar que um dia esta composição eletrônica do jornal seja diretamente recebida e lida em uma tela, ao menos por uma parte dos leitores?" (CHARTIER, 1999a, p. 138).

Se ao longo do tempo os suportes textuais apresentam uma evolução, fica evidente também que sedimentam características que irão definir suas identidades, como a paginação, localização no espaço impresso, tudo isso de forma bastante linear. Essa noção de criação de identidades é fundamental para o produto, visto que passa a criar e manter uma ligação constante com seu público. Essa noção é apontada como fundamental para a constituição do contrato de leitura (VERÓN, 1985).

Para o emissor, essa noção de contrato baseia-se num leque de "obrigações" ou constrangimentos discursivos a serem respeitados; para o receptor, há, por meio das estratégias do emissor, o reconhecimento de suas intenções, por exemplo, no tocante à linguagem usada, o que pode marcar tanto a aproximação quanto o distanciamento em relação ao público. Este posicionamento entre a instância de produção e de reconhecimento é estabelecida, segundo a análise discursiva, pela construção e disposição dos sujeitos discursivos enunciador e destinatário, ou coenunciador.

A consolidação dos elementos capazes de conferir essa identidade ao produto, e dessa forma permitir o reconhecimento por parte de seu público, finda por estabelecer essa noção contratual, que assegura o contato com o leitor, ou o consumo de um produto. E agora, mediante as novas possibilidades dos produtos digitais, é possível falar dessa noção contratual? Há modalidades formais que permitam esse reconhecimento?

Os produtos digitais, em sua essência, também dependem de um suporte, pelo menos para o instante de consumo. Pode-se falar da tela do computador, ou do e-book, ${ }^{3}$ que já conta com um suporte próprio, como o leitor Librié, lançado pela Sony. Esse leitor apresenta o mesmo tamanho e peso de um livro normal, podendo armazenar em média vinte livros.

Sobre o livro eletrônico e sua relação com as modalidades de suporte, Chartier (2002, p. 112) apresenta uma indagação acerca " $\mathrm{da}$ capacidade que teria esse novo livro para encontrar ou produzir seus leitores". A indagação do autor, na verdade, é sobre a noção de contrato de leitura que essas novas modalidades de suporte poderiam estabelecer com seus públicos, já tradicionalmente habituadas à relação com formatos consolidados. É claro que ainda estamos diante de um fato parcialmente conhecido. A realidade dos produtos digitais ainda não está estabilizada e na maioria das vezes ficamos como que tateando no escuro, em meio a suposições acerca do devir, por ora apenas parcialmente conhecido.

O texto, na condição de matéria significante, é o mesmo, independentemente do suporte. $\mathrm{O}$ que muda, na verdade é sua forma de apresentação e disponibilização. Para Chartier (1999a, p. 138), "mesmo que seja exatamente a mesma matéria editorial a fornecida eletronicamente, a organização e a estrutura da recepção são diferentes, na medida em que a paginação do objeto impresso é diversa da organização permitida pela consulta dos bancos de dados informáticos".

Tem-se aí pontuada a ideia de que o novo suporte digital suscita uma nova forma de apresentação do texto. Esse texto, por meio de sua forma de disponibilização, sugere novas maneiras de ser recebido e consumido. É essa a noção de uma performance, e não apenas de leitura, associada a uma noção de texto. De acordo com a evolução do suporte do texto, essa perspectiva

\footnotetext{
3 A lista dos e-books mais vendidos da Amazon.com inclui uma mistura eclética que vai de livros de negócios a manuais de sexo. A maioria custa entre US\$ 4 e US $\$ 10$ cada, podendo ser lido em notebooks comuns ou computadores de mão como o Palm, ou modelos de outros fabricantes que usam o Windows. A lista dos mais vendidos desse ano incluem "O código Da Vinci", de Dan Brown e "Van Helsing", de Kevin Ryan. www.revistadigital.com.br
}

Rev. Estud. Comun., Curitiba, v. 10, n. 21, p. 59-67, jan./abr. 2009 
fica mais óbvia, visto que o texto, por sua estética, pela leitura pode provocar 'reações', dependendo de uma maior ou menor liberdade em relação ao suporte, que pode deixar o indivíduo mais ou menos liberado para a fruição da obra. "Constatase uma implicação forte do corpo, mas essa implicação se manifesta segundo modalidades superficialmente (e em aparência) muito diferentes, definindo-se com a ajuda de um pequeno número de traços idênticos" (ZUMTHOR, 2000, p. 40).

Ao localizar na obra, entendida como indissociada do suporte, essa possibilidade de um uso que provoca uma fruição que se manifesta num corpo sensível, que vibra, está se plasmando uma nova realidade, que marca um profundo encontro entre o texto e seu leitor. "É nessa perspectiva que tento perceber que na minha leitura dos textos dos quais extraio minha alegria está parte do meu corpo" (ZUMTHOR, 2000, p. 73).

Sendo assim, encontramo-nos diante de um impasse vivido pela comunicação de massa. Agora, as tecnologias possibilitam uma difusão dos conteúdos de forma distinta, podendo moldar um mesmo material para públicos diferentes, pensandose nessas outras modalidades de leitura, de acordo com cada perfil, base da comunicação segmentada. O texto, enquanto matéria significante permanece. A mudança desafiadora fica por conta da instância emissora, para a qual "a diferença pode decorrer de uma decisão do editor, que, em uma era de complementaridade, de compatibilidade ou de concorrência dos suportes, pode visar com isso diferentes públicos e diversas leituras" (CHARTIER, 1999a, p. 138).

Dessa forma, o que se pode esperar da nova noção de contrato de leitura, senão a necessidade de um tempo para que se consolide. A percepção de um público disperso e a possibilidade de atendê-lo torna-se sedutora. É essa de fato uma das grandes revoluções de nosso tempo.

A revolução do texto eletrônico será ela também uma revolução da leitura. Ler sobre uma tela não é ler um códex. Se abre possibilidades novas e imensas, a representação eletrônica dos textos modifica totalmente a sua condição: ela substitui a materialidade do livro pela imaterialidade de textos sem lugar específicos; às relações de contigüidade estabelecidas no objeto impresso ela opõe a livre composição de fragmentos indefinidamente manipuláveis; à captura imediata da totalidade da obra, tornada visível pelo objeto que a contém, ela faz suceder a navegação de longo curso entre arquipélagos textuais sem margens nem limites. Essas mutações comandam, inevitavelmente, imperativamente, novas maneiras de ler, novas relações com a escrita, novas técnicas intelectuais (CHARTIER, 1999b, p. 100-101).

Em seu conjunto, essas novas modalidades de relacionamento com o texto marcam um novo campo sobre o qual se deve debruçar, não apenas buscando-se formas de intervir. Deve-se em especial buscar entender as reais dimensões desse processo, que ao habilitar novas formas de acessar e ler conteúdos, na verdade revela-se que a partir da ideia de unicidade de uma obra, agora se percebe o quão fragmentada ela é. À já tradicional percepção da obra como elemento fragmentário, decorrente das leituras distintas, soma-se agora a constatação de que se estilhaçam também as formas de acesso ao conteúdo.

Na concepção semiótica, o texto apresentase como elemento que convoca o leitor ao processo de significação, sugerindo itinerários de leitura e interpretação. $\mathrm{Na}$ contemporaneidade, ao se falar da semiótica textual deve-se considerar também as implicações dos suportes materiais, visto que cada vez mais o texto encontra espaço, por exemplo, em ambientes virtuais. A constante evolução das tecnologias da comunicação tem propiciado um campo fértil para a experimentação de novos formatos e linguagens textuais. Um texto numa página web, por exemplo, assume novas características, como a fluidez, além de ser caracterizado pelo encontro entre modalidades textuais: texto, áudio, imagem (estática e em movimento), ligando-se a outros blocos, na perspectiva hipertextual.

A proposta de se pensar as possibilidades de significação oferecidas pelo signo encontram-se ampliadas, pois os vários canais que possibilitam a circulação de mensagens encontram-se disponíveis ao leitor numúnico suporte. Um exemplo emblemático é oferecido pela diagramação, ou o "desenho da informação", que de uma arte estática, ao chegar à rede incorpora outras linguagens, passando ao que se chama produção gráfica animada (MANOVICH, 2006; SANTAELLA, 2008). A página web de um jornal, além das mobilidades e fluidez marcada pelos links, pode apresentar elementos com animação que, em numa ideia de conjunto, oferece ao leitoritinerários de leitura e possibilidades de interpretação em constante ampliação. 


\section{REFERÊNCIAS}

CHARTIER, R. A aventura do livro: do leitor ao navegador. São Paulo: Ed. da UNESP, 1999a.

A ordem dos livros: leitores, autores e bibliotecas na Europa entre os séculos XIV e XVIII. Brasília: Ed. da UnB, 1999b.

Os desafios da escrita. São Paulo: Ed. da UNESP, 2002.

CHOMSKY, N. Topics in the theory of generative grammar. Haya: Mouton, 1969.

DUBOIS, J. Dicionário de lingüística. São Paulo: Cultrix, 1997.

ECO, H. O conceito de texto. São Paulo: Ed. da EDUSP, 1984.

Seis passeios pelo bosque da ficção. São Paulo: Cia. das letras, 1994.

MANOVICH, L. Import/export: design workflow and contemporay aesthetics. 2006. Disponível em: $<$ http:/www.manovich.net>. Acesso: em 19 mar. 2009.

SANTAELLA, L. A teoria geral dos signos: como as linguagens significam as coisas. São Paulo: Pioneira, 2000. A estética das linguagens líquidas. In: SANTAELLA, L.; ARANTES, P. (Org.). Estéticas tecnológicas: novos modos de sentir. São Paulo: Ed. da EDUC, 2008. p. 207-230.

SAUSSURE, F. de. Curso de lingüística geral. São Paulo: Cultrix, 2006.

VERÓN, E. Lanalyse du "contrat de lecture": une nouvelle méthode pour les études de positionnement des supports presse. In: Les medias. Expériences, recherches actuelles, applications. Paris: Irep, 1985. p. 203-229.

ZUMTHOR, P. Performance, recepção e leitura. São Paulo: Ed. da EDUC, 2000.

Recebido: 23/03/2009 Received: 03/23/2009

Aprovado: 06/05/2009 Approved: 05/06/2009

Revisado: 30/10/2009

Reviewed: 10/30/2009 